\title{
Acute Modulation of Adipose Tissue Lipolysis by Intravenous Estrogens
}

\author{
Rachael E. Van Pelt ${ }^{*}$, Wendolyn S. Gozansky ${ }^{*}$, Robert C. Hickner ${ }^{\dagger}$, Robert S. Schwartz ${ }^{*}$, and \\ Wendy M. Kohrt ${ }^{*}$ \\ "Department of Medicine, Division of Geriatric Medicine, University of Colorado at Denver and \\ Health Sciences Center, Denver, Colorado \\ tDepartments of Exercise and Sports Science, and Physiology, East Carolina University, Greenville, \\ North Carolina
}

\section{Abstract}

Objective-The aim of this study was to determine whether intravenous (IV) conjugated estrogens (EST) acutely enhance the suppression of whole-body or regional subcutaneous adipose tissue (SAT) lipolysis by insulin in postmenopausal women.

Research Methods and Procedures-We assessed whole-body lipolysis by $\left[{ }^{2} \mathrm{H}_{5}\right]$ glycerol rate of appearance ( $\mathrm{Glyc}_{\mathrm{RA}}$ ) and abdominal and femoral SAT lipolysis (interstitial glycerol; Glyc $\mathrm{c}_{\mathrm{IS}}$ ) by subcutaneous microdialysis. Postmenopausal women $(n=12)$ were studied on two occasions, with IV EST or saline control (CON), under basal conditions and during a 3 -stage $\left(4,8\right.$, and $40 \mathrm{mU} / \mathrm{m}^{2} /$ min) hyperinsulinemic, euglycemic clamp. Ethanol outflow/inflow ratio and recovery of $\left[{ }^{13} \mathrm{C}\right]$ glycerol during microdialysis were used to assess blood flow changes and interstitial glycerol concentrations, respectively.

Results-Compared with CON, EST did not affect systemic basal or insulin-mediated suppression of lipolysis $\left(\mathrm{Glyc}_{\mathrm{RA}}\right.$ ) or SAT nutritive blood flow. Basal Glyc $\mathrm{IS}_{\mathrm{IS}}$ in SAT was reduced on the EST day. However, insulin-mediated suppression of lipolysis in SAT was not significantly influenced by EST.

Discussion-These findings suggest that estrogens acutely reduce basal lipolysis in SAT through an unknown mechanism but do not alter whole-body or SAT suppression of lipolysis by insulin.

\section{Keywords}

subcutaneous adipose tissue; abdominal; femoral; interstitial glycerol; postmenopausal women

\section{Introduction}

Suppression of sex hormones in premenopausal women triggers an increase in adiposity with a disproportionate increase in central fat mass $(1,2)$. Similarly, postmenopausal women on placebo treatment have an increased rate of fat accumulation, particularly in the abdominal region, when compared with estrogen-treated women (3-6). These observations suggest that fat accumulation occurs more readily in the estrogen-deficient state in a region-specific manner. The mechanisms for these actions of estrogens remain unclear, but increased fat 
accumulation in the estrogen-deficient state could occur through enhanced triglyceride storage, reduced fatty acid mobilization (i.e., lipolysis), and/or decreased fat oxidation. Further, it is not known whether estrogens modulate fat accumulation by altering lipolysis during basal conditions or in response to stimulation (e.g., $\beta$-adrenergic) or inhibition (e.g., insulin, $\alpha$ adrenergic). In vitro studies have demonstrated that femoral adipocytes are less lipolytic than abdominal adipocytes as a result of increased sensitivity to insulin and $\alpha$-adrenergic inhibition (7-11). However, it is not known whether estrogens preferentially inhibit femoral lipolysis to favor gluteal-femoral subcutaneous adipose tissue (SAT) ${ }^{1}$ accumulation, the predominant region of fat storage in premenopausal women.

We and others have found that exogenous estrogens improve the glucoregulatory action of insulin (12-14), even when administered acutely (14). However, there is a paucity of research on the effect of estrogens on the anti-lipolytic action of insulin in humans. The importance of determining whether estrogens improve the anti-lipolytic action of insulin is highlighted by the contribution that adipocyte insulin resistance has on the pathogenesis of type 2 diabetes (15). Moreover, the importance of conducting studies in humans is underscored by findings that the regulation of adipose tissue metabolism by sex steroids is not uniform across species (16). To our knowledge, the only study that has evaluated estrogen regulation of lipolysis in postmenopausal women found that 2 months of transdermal estradiol treatment decreased basal whole-body lipolysis but not adrenergic stimulation of lipolysis; suppression of lipolysis by insulin was not measured (17). Although the measurement of whole-body glycerol appearance is a good index of overall adipose tissue lipolysis, it cannot elucidate regional differences in SAT lipolysis and includes glycerol derived from the hydrolysis of circulating triglycerides. Thus, by directly measuring regional SAT lipolysis in vivo, we gain additional information regarding the specific contribution of SAT lipolysis to net lipolytic activity. Further, by administering estrogens intravenously, we were able to measure the acute effect on the antilipolytic action of insulin in the absence of confounding factors that are introduced during chronic administration of estrogens. We assessed the direct effect of estrogens on insulin action independently of the first-pass hepatic effects of oral estrogens, opposition by progestins, and estrogen-mediated changes over time in body composition.

The primary aim of the current study was to determine whether acute intravenous (IV) administration of conjugated estrogens (EST) influences whole-body and regional SAT lipolysis during basal conditions and during suppression by insulin. We hypothesized that IV EST would enhance both whole-body and regional SAT suppression of lipolysis by insulin. To test these hypotheses, we measured whole-body $\left(\left[{ }^{2} \mathrm{H}_{5}\right]\right.$ glycerol kinetics) and regional (microdialysis of abdominal and femoral SAT) lipolysis under basal conditions and during a 3 -stage hyperinsulinemic, euglycemic clamp procedure in postmenopausal women with and without IV EST administration.

\section{Research Methods and Procedures}

\section{Study Design}

Whole-body lipolysis $\left(\left[{ }^{2} \mathrm{H}_{5}\right]\right.$ glycerol rate of appearance; $\left.\mathrm{Glyc}_{\mathrm{RA}}\right)$ and abdominal and femoral SAT lipolysis (interstitial glycerol; $\mathrm{Glyc}_{\mathrm{IS}}$ ) were assessed in postmenopausal women on two occasions, with (EST) and without [control (CON)] acute administration (IV bolus) of conjugated estrogens $(2.5 \mathrm{mg}$ ). Measurements were made under basal conditions and during a 3-stage hyperinsulinemic, euglycemic clamp (Figure 1). A qualitative index of SAT nutritive blood flow (ethanol washout) was measured simultaneously with Glyc Is.

\footnotetext{
${ }^{1}$ Nonstandard abbreviations: SAT, subcutaneous adipose tissue; IV, intravenous; EST, estrogen; GlycRA, glycerol rate of appearance; GlycIS, interstitial glycerol concentration; CON, control; GCRC, General Clinical Research Center; FFA, free fatty acid; RR, relative recovery; Epi, epinephrine; NEpi, norepinephrine; OVX, ovariectomized.
} 


\section{Subjects}

Twelve healthy, postmenopausal women not on hormone therapy were studied.

Postmenopausal status was defined as cessation of menses for at least one year, or hysterectomy with a follicle stimulation hormone $>30 \mathrm{IU} / \mathrm{L}$. Women were excluded from the study if they had: a history of hormone-sensitive cancer, fasting plasma glucose $>7.0 \mathrm{mM}$, uncontrolled hypertension (resting systolic blood pressure $>150 \mathrm{~mm} \mathrm{Hg}$ or diastolic $>90 \mathrm{~mm} \mathrm{Hg}$ ), thyroid dysfunction ( $\mathrm{TSH}<0.5$ or $>5.0 \mathrm{mU} / \mathrm{L}$ ), hypertriglyceridemia (fasting triglycerides $>4.5 \mathrm{mM}$ ), or abnormal liver or renal function. The nature, purpose, and risks of the study were explained verbally and in writing to each subject. All participants provided written informed consent to participate in the study, which was approved by the Colorado Multiple Institutional Review Board.

\section{Body Composition}

Total fat mass was determined by DXA using a Lunar DPX-IQ (Software v4.38, Lunar Co., Madison, WI). Waist circumferences were measured by the same technician at the narrowest point between the lowest rib and the iliac crest.

\section{Hyperinsulinemic, Euglycemic Clamp Procedure}

Three-stage $\left(4,8\right.$, and $\left.40 \mathrm{mU} / \mathrm{m}^{2} / \mathrm{min}\right)$ hyperinsulinemic, euglycemic clamps were administered according to the methods of DeFronzo et al. (18) (Figure 1). Clamps were performed at the General Clinical Research Center (GCRC) after a 12-hour fast. An IV catheter was placed in an antecubital vein for the infusion of insulin and 20\% dextrose. A second catheter was placed retrograde to venous flow in the contralateral hand for blood sampling. The hand was kept in a warming box maintained at $60{ }^{\circ} \mathrm{C}$ to produce arterialized blood samples (19). After the 90-minute basal period, insulin was infused at a priming dose for 10 minutes (stepped down each minute from $12 \mathrm{mU} / \mathrm{m}^{2} / \mathrm{min}$ ) and then at a constant rate of $4 \mathrm{mU} / \mathrm{m}^{2} / \mathrm{min}$ for 80 minutes. For the second and third stages, the insulin infusion was increased to 8 and $40 \mathrm{mU} /$ $\mathrm{m}^{2} / \mathrm{min}$, respectively, for 90 minutes. Additionally, a primed $(1.5 \mu \mathrm{mol} / \mathrm{kg})$, constant $(\sim 0.1$ $\mu \mathrm{mol} / \mathrm{kg} / \mathrm{min}$ ) infusion of $\left[{ }^{2} \mathrm{H}_{5}\right]$ glycerol (Cambridge Isotope Laboratories, Inc., Andover, MA) was delivered for 360 minutes (90-minute basal period and 90 minutes at each insulin stage) to measure whole-body lipolysis. Plasma glucose concentration was measured every 5 minutes during the insulin infusion by the glucose oxidase method on an automated glucose analyzer (YSI Instruments, Yellow Springs, OH). The dextrose infusion was adjusted to maintain plasma glucose at $5 \mathrm{mM}$. Blood samples were collected at time 0 (fasting) and at 60,75 , and 90 minutes of the basal period and each insulin stage for determination of insulin, estradiol, estrone, catecholamines, free fatty acids (FFAs), and glycerol (concentration and isotope enrichment). The clamp procedure was performed on two occasions (random order) in each woman, with (EST) and without (CON) a $2.5 \mathrm{mg}$ IV bolus of conjugated estrogens (Premarin, Wyeth Pharmaceuticals Inc., Philadelphia, PA) administered at the beginning of the basal period. The bolus was administered after the time 0 blood samples were collected and immediately before the tracer infusion was initiated on the EST day. An average of $4 \pm 2$ weeks separated the two testing days. The investigator and nursing staff conducting the clamps were not blinded to the EST administration, but all blood and dialysate samples were analyzed in a blinded fashion.

\section{Whole-body Lipolysis}

Plasma glycerol concentrations were measured by the GCRC Core Laboratory. The analysis of $\left[{ }^{2} \mathrm{H}_{5}\right]$ glycerol was done by the Colorado Clinical Nutrition Research Unit Mass Spectrometry Core Laboratory using a modification of the negative ion chemical ionization gas chromatography-mass spectrometry as previously described (20). The Glyc $\mathrm{RA}_{\mathrm{RA}}$ over the last 30 minutes of each stage was calculated using the non-steady-state equation of Steele (21): 


$$
R_{\mathrm{a}}=\mathrm{F}-\mathrm{pV}\left[\left(\mathrm{C}_{2}+\mathrm{C}_{1}\right) / 2\right]\left[\left(\mathrm{E}_{2}-\mathrm{E}_{1}\right)\left(\mathrm{t}_{2}-\mathrm{t}_{1}\right)\right] /\left[\left(\mathrm{E}_{2}+\mathrm{E}_{1}\right) / 2\right]
$$

where $\mathrm{F}$ is the rate of infusion for $\left[{ }^{2} \mathrm{H}_{5}\right]$ glycerol $(0.10 \mu \mathrm{mol} / \mathrm{kg} / \mathrm{min}), \mathrm{pV}$ is the volume of distribution $(0.027 \mathrm{~L} / \mathrm{kg}), \mathrm{C}$ is the plasma glycerol concentration $(\mu \mathrm{mol})$, E is the plasma isotope enrichment, and $\mathrm{t}$ is time ( $\mathrm{min})$. Due to technical difficulty detecting $\left[{ }^{2} \mathrm{H}_{5}\right]$ glycerol in samples from 2 study participants (basal period samples for one woman and stage 2 samples for another), complete $\mathrm{Glyc}_{\mathrm{RA}}$ data were available for only 10 subjects. Thus, only these 10 paired sets of Glyc RA data are presented. Exclusion of these 2 women from the analysis of plasma glycerol concentrations did not alter our results, therefore all 12 paired sets of plasma glycerol are presented.

\section{Regional SAT Lipolysis}

Regional SAT lipolysis was evaluated by placing linear microdialysis probes (BAS custom LM-3 probes, $3 \mathrm{~cm}$ membrane; BAS, Inc., West Lafayette, IN) in both abdominal and femoral SAT. The microdialysis probes were soaked and perfused for a minimum of 14 hours overnight in 5\% ethanol and Ringer solution to remove the protective glycerol coating on the dialysis membrane. On the morning of the clamp, microdialysis probes were perfused for an additional 30 minutes in Ringer solution to flush the ethanol solution. Probes were inserted under sterile conditions into abdominal ( 2 probes lateral to the umbilicus; $\sim 3 \mathrm{~cm}$ apart) and femoral ( 2 probes mid-thigh; $\sim 3 \mathrm{~cm}$ apart) SAT. Throughout the insulin clamp procedure, the probes were perfused at $2.0 \mu \mathrm{L} / \mathrm{min}$ with Ringer solution containing $2.5 \mathrm{mM}$ glucose, $200 \mu \mathrm{M}\left[{ }^{13} \mathrm{C}\right]$ glycerol, and $5 \mathrm{mM}$ ethanol. No samples were collected for at least 60 minutes after probe insertion to allow for equilibration of the microdialysis system and to allow sufficient time for initial trauma (i.e., local hyperemia) of probe insertion to subside (22). Glucose was included in the perfusate to minimize the concentration gradient-mediated flow of glucose out of the interstitial fluid. Ethanol was included in the perfusate to detect qualitative changes in nutritive blood flow in the region surrounding the probe, as previously described (23). Ethanol concentrations in the dialysates and perfusates were measured fluorometrically, and the data were expressed as the outflow/inflow ratio ([ethanol $]_{\text {dialysate }} /[\text { ethanol }]_{\text {perfusate }}$ ), which is inversely related to nutritive blood flow. The outgoing dialysate was collected in 15-min fractions $(30 \mu \mathrm{L})$ throughout the basal period and each insulin stage. Dialysate samples were initially stored at $4{ }^{\circ} \mathrm{C}$ and analyzed within 24 hours for ethanol concentrations. Dialysate samples were then stored at $-80^{\circ} \mathrm{C}$ and sent in batch to a commercial mass spectrometry laboratory (Metabolic Solutions, Inc., Nashua, $\mathrm{NH}$ ) for the analysis of $\left[{ }^{13} \mathrm{C}\right]$ glycerol enrichments and to East Carolina University (Greenville, NC) for the spectophotometric measurement of glycerol concentrations using an automated CMA600 Microdialysate Analyzer (CMA Microdialysis, Acton, MA). Because the measurement of glycerol concentration by microdialysis is not a direct measure of interstitial glycerol, $\left[{ }^{13} \mathrm{C}\right]$ glycerol isotopic tracer was included in the perfusate to calibrate dialysate concentrations to the degree of equilibration of interstitial glycerol across the probe membrane, as previously described (24). Thus, as an internal reference, relative recovery (RR) of glycerol across the dialysis membrane was determined from the isotopic enrichment of $\left[{ }^{13} \mathrm{C}\right] \mathrm{glycerol}$

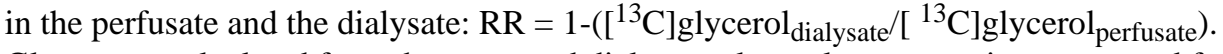
Glyc $_{\text {IS }}$ was calculated from the measured dialysate glycerol concentrations corrected for the RR of each probe at each individual time-point and then averaged over the final 30 min (2 15min collections) of each clamp stage and within each SAT region (across the two probes).

\section{Blood Hormones and Metabolites}

Blood samples were stored at $-80{ }^{\circ} \mathrm{C}$ and analyzed in batch by the Core Laboratory of the GCRC. Serum insulin concentrations were determined with a double-antibody radioimmunoassay (Pharmacia Upjohn, Kalamazoo, MI). Plasma glycerol (R-Biopharm, 
Marshall, MI) and FFA (Wako Chemicals, Inc., Richmond, VA) were determined enzymatically. Plasma estradiol and estrone were determined by double-antibody radioimmunoassay (DPC, Los Angeles, CA, and DSL, Webster, TX; respectively). Plasma epinephrine (Epi) and norepinephrine (NEpi) concentrations were determined by highperformance liquid chromatography with electrochemical detection (Dionex DX-500; Dionex, Sunnyvale, CA). Intra- and inter-assay coefficients of variation were as follows: insulin, 5.2\% and $9 \%$; glycerol, $3.4 \%$ and $17.3 \%$; FFA, $1.3 \%$ and $5.6 \%$; estradiol, $6.0 \%$ and $11.2 \%$; estrone, $8.7 \%$ and $8.6 \%$; Epi, $5.7 \%$ and $8.5 \%$; and NEpi, $4.1 \%$ and $7.7 \%$. With the exception of insulin and glucose data which were analyzed immediately, hormone and metabolite data for both study days were batched for each subject and analyzed together.

\section{Blood Lipids and Lipoproteins}

Measurements of serum lipid and lipoprotein concentrations were done by the GCRC Core Laboratory. Total cholesterol, high-density lipoprotein cholesterol, and triglycerides were measured by automated enzymatic commercial kits on a Cobra Mira Plus instrument (Roche Diagnostic Systems, Indianapolis, IN). Intra- and inter-assay coefficients of variation were as follows: total cholesterol, 5.1\% and 2.4\%; high-density lipoprotein cholesterol, $4.5 \%$ and 2.9\%; triglycerides, $1.4 \%$ and $3.3 \%$. Low-density lipoprotein cholesterol was calculated using the Friedewald equation (25).

\section{Statistics}

Because this was the first study, to our knowledge, to evaluate the effect of estrogen on the anti-lipolytic action of insulin, there were no data from which to estimate an effect size. Our sample size of 12 was based on having power to detect an effect of estrogen on insulin-mediated glucose disposal (14). Paired $t$ tests were used to evaluate differences in serum hormone and metabolite concentrations between EST and CON at time 0 . A two-way (day $\times$ stage) repeated measures ANOVA was used to evaluate changes in plasma glycerol concentrations, $\mathrm{Glyc}_{\mathrm{RA}}$, FFA, Epi, NEpi, and insulin between days (EST vs. CON) and across insulin stages (basal period and stages 1,2, and 3). A three-way (SAT region $\times$ day $\times$ stage) repeated measures

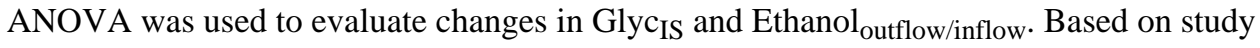
results, the power to detect an interaction between estrogen and insulin on Glyc $\mathrm{RA}_{\mathrm{R}}$ was low (8\%). Main effects were considered when interactions were not significant. Statistical significance was set at $\alpha=0.05$. Results are presented as mean \pm standard deviation, unless otherwise specified. All statistical analyses were conducted using SPSS for Windows software (v12.0; SPSS, Inc., Chicago, IL).

\section{Results}

Subject characteristics are presented in Table 1 . On average, women were moderately overweight with abdominal obesity, as indicated by the large waist girth $(>88 \mathrm{~cm})$ but were not hypertriglyceridemic $(<1.7 \mathrm{mM})$. The IV bolus of EST successfully raised plasma estradiol and estrone concentrations (Figure 2), such that mean estradiol concentrations throughout the hyperinsulinemic, euglycemic clamp were comparable to premenopausal, mid-luteal phase levels. At time 0, before EST infusion, there were no significant differences in serum hormone and metabolite concentrations between the two test days, although plasma glycerol tended to be lower on the EST day, compared with the CON day ( $74 \pm 17$ vs. $82 \pm 25 \mu \mathrm{M}, p=0.10$ ). Mean time 0 and end-stage (average of 60,75, and 90 min samples) serum hormone and metabolite concentrations during the clamp are presented in Table 2. With the exception of significantly lower plasma insulin during stage 3 on the EST day, there were no other ESTrelated differences across the clamp stages in glucose, insulin, Epi, NEpi, or FFA. We previously reported the effects of IV EST to reduce insulin concentrations without a decrease in glucose disposal rates (14). 


\section{Whole-body Lipolysis}

There were no significant treatment day $x$ insulin stage interactions for glycerol concentrations or Glyc $\mathrm{RA}_{\mathrm{RA}}$. As expected, there was a dose-dependent main effect $(p<0.01)$ of insulin to suppress serum glycerol concentrations and $\mathrm{Glyc}_{\mathrm{RA}}$ with increasing levels of hyperinsulinemia on both EST and CON days (Figure 3). There was a trend for a main effect $(p=0.09)$ of EST to reduce plasma glycerol concentrations that reflected the trend for glycerol to be lower at time 0 (i.e., before the administration of EST). There were no significant main effects of EST on whole-body basal or insulin-mediated suppression of lipolysis $\left(\mathrm{Glyc}_{\mathrm{RA}}\right)$. Insulin concentrations were significantly reduced on the EST day compared with the CON day during the third insulin stage, but $\mathrm{Glyc}_{\mathrm{RA}}$ was not different, suggesting greater anti-lipolytic action of insulin on the EST day. However, adjusting Glyc $_{\mathrm{RA}}$ for differences in insulin concentrations did not significantly alter the results (data not shown).

\section{Regional SAT Lipolysis}

Changes in nutritive blood flow (Figure 4) over time did not significantly differ between sites (femoral vs. abdominal), between conditions (EST vs. CON), or across insulin stages. There were no significant interactions (SAT region $\times$ day $\times$ stage) for Glyc IS $_{\text {. As expected, there was }}$ a significant dose-dependent main effect $(p<0.001)$ of insulin to suppress Glyc $_{I S}$ in both abdominal and femoral SAT (Figure 5). There was a significant main effect $(p=0.001)$ of fat region, such that $\mathrm{Glyc}_{\mathrm{IS}}$ was higher in femoral than in abdominal SAT. There was also a significant main effect of day $(p<0.05)$, such that Glyc IS was lower on the EST day compared with the CON day in femoral SAT $(270 \pm 34$ vs. $331 \pm 49 \mu \mathrm{M})$ and abdominal SAT $(255 \pm 40$ vs. $286 \pm 52 \mu \mathrm{M})$.

\section{Discussion}

The major findings of this study were that acute IV administration of EST reduced basal Glyc $_{\text {IS }}$ in both femoral and abdominal SAT, presumably reflecting a suppression of basal lipolysis. However, whole-body basal lipolysis $\left(\mathrm{Glyc}_{\mathrm{RA}}\right)$ was not significantly influenced by EST. Contrary to our hypotheses, EST also did not alter whole-body or regional (abdominal and femoral SAT) suppression of lipolysis by insulin. To our knowledge, the current study was the first to evaluate whole-body and regional SAT lipolysis in response to acute EST administration. Although we previously observed an acute effect of EST to improve the wholebody glucoregulatory action of insulin (14), the present analysis found no significant effects of EST on the whole-body or regional SAT anti-lipolytic action of insulin. Further, we previously observed an acute effect of EST to reduce serum glycerol concentrations during hyperinsulinemia (14), but the present analysis revealed no change in $\mathrm{Glyc}_{\mathrm{RA}}$. The lack of change in $\mathrm{Glyc}_{\mathrm{RA}}$, despite reduced insulin concentrations during the third insulin stage, suggested an increased sensitivity to the anti-lipolytic action of insulin. However, $\mathrm{Glyc}_{\mathrm{RA}}$ adjusted for insulin concentration was not different on the CON and EST days. Thus, the reduced serum glycerol (adjusted for insulin concentrations) that we previously observed in response to acute estrogen administration (14) may have reflected an increased clearance of glycerol from the circulation.

\section{Estrogens and Whole-body Lipolysis}

Limited data are available regarding the in vivo effects of estrogens on lipolysis. A previous study of postmenopausal women demonstrated that basal whole-body lipolysis was suppressed in response to 2 months of transdermal estradiol treatment (13). In contrast, in our current study, basal whole-body lipolysis was not altered in response to acute IV conjugated estrogen administration, suggesting that duration of estrogen exposure or the route of administration may be important. We are not aware of any published studies that have evaluated the effects of estrogen therapy on insulin-mediated suppression of lipolysis. 


\section{Estrogens and Regional Adipose Tissue Metabolism}

Studies of sex hormone administration or suppression highlight the importance of estrogens as a determinant of regional fat accumulation. Postmenopausal women treated with exogenous estrogens have demonstrated an attenuated rate of fat accumulation compared with those on placebo $(6,26-28)$. The attenuation of fat accumulation by estrogens may be specific to the abdominal region, since leg fat mass either did not change (28) or increased (26) in response to hormone treatment. Additionally, in premenopausal women treated with a gonadotropinreleasing hormone agonist for 4 months to suppress endogenous sex hormones, there were significant increases in trunk ( $7.5 \%$ to $10 \%)$ but not leg $(<2 \%)$ fat mass $(2,29)$. Taken together, these previous studies support a role for estrogens in the regulation of regional fat accumulation, such that excess fat is stored in the gluteal-femoral, rather than the abdominal, region in the estrogen-sufficient state. Consistent with these studies, the acute administration of estrogens to postmenopausal women appeared to reduce basal lipolysis in SAT, particularly in the femoral region, supporting a role for estrogens in regional fat deposition.

The mechanisms by which estrogens regulate regional fat metabolism remain uncertain. Studies of changes in regional lipolysis in response to sex-hormone perturbations are lacking. To our knowledge, the current study was the first to manipulate estrogens prospectively to evaluate changes in abdominal and femoral SAT lipolysis (interstitial glycerol rate of appearance) in humans. Previous cross-sectional studies of menopause-related differences in regional adipocyte lipolysis in vitro have yielded conflicting results. One study observed higher sensitivity to $\beta$-adrenergic stimulation of lipolysis in subcutaneous abdominal adipocytes than in femoral adipocytes from premenopausal, but not postmenopausal, women (30). This might suggest that the protection against abdominal fat accumulation in premenopausal women is linked to the ability to mobilize fatty acids from that region. However, in a comparison of periand postmenopausal women, there were no differences in $\beta$-adrenergic stimulation of lipolysis in either subcutaneous abdominal or gluteal adipocytes (31). These cross-sectional comparisons do not reveal definitive mechanisms for menopause-related differences in regional adipocyte metabolism, and, to our knowledge, there have been no published studies of the effects of sex hormone suppression or estrogen therapy comparing both abdominal and femoral SAT lipolysis in humans. Thus, our prospective study provides novel preliminary data for an effect of estrogens on regional SAT lipolysis in postmenopausal women.

To our knowledge, the only study that has evaluated the effect of estrogens on regional SAT lipolysis in vivo used rodents and assessed only adrenergic-mediated lipolysis. Darimont et al. (32) used microdialysis to assess $\beta$-adrenergic stimulation of lipolysis in vivo in parametrial adipose tissue of ovariectomized (OVX) rats. They found that 7 days of estradiol treatment increased isoproterenol-stimulated lipolysis in OVX rats back to pre-OVX diestrous levels, suggesting an effect of estradiol on adipose tissue $\beta$-adrenergic stimulation. Because the regulation of adipose tissue metabolism by sex steroids is not uniform across species (16), it is not clear whether these results are relevant to humans. However, there is some evidence to support a role of estrogens in adrenergic-mediated SAT lipolysis. Pederson et al. (33) evaluated the effects of estradiol on abdominal $\alpha 2$-adrenergic receptor mRNA expression in subcutaneous and visceral abdominal adipose tissue samples obtained from postmenopausal women undergoing surgery for severe obesity (gastric banding). They found that estradiol acutely (24-h in vitro incubation) up-regulated anti-lipolytic $\alpha 2$-adrenergic receptors in subcutaneous, but not visceral, abdominal adipose tissue. This would suggest a greater antilipolytic responsiveness in abdominal subcutaneous compared with visceral adipose tissue. The effect of estradiol on femoral adipocyte $\alpha 2$-adrenergic receptors was not studied (33). Thus, estradiol may affect SAT lipolysis through adrenergic-mediated mechanisms, but there are not sufficient data to draw firm conclusions. Importantly, none of the aforementioned studies (30-33) evaluated insulin-mediated suppression of lipolysis, a significant gap in the 
literature given the importance of adipocyte-mediated effects in the progression of insulin resistance (15). The current study was the first to evaluate whether estrogens affect insulinmediated suppression of lipolysis in abdominal and femoral SAT in postmenopausal women.

Although our in vivo data do not support a role for IV estrogens to acutely alter insulin-mediated suppression of lipolysis in femoral or abdominal SAT of postmenopausal women, estrogens reduced basal lipolysis (as measured by Glyc $\mathrm{IS}_{\mathrm{S}}$ ) $16 \%$ in femoral SAT and $\sim 8 \%$ in abdominal SAT. If this reduction in SAT lipolysis persists with prolonged estrogen treatment, this would suggest that estrogens suppress the mobilization of FFA from SAT during basal conditions, which could be a contributing mechanism for the propensity of premenopausal women to accumulate SAT, particularly in the femoral region. Additionally, basal lipolysis was lower in abdominal than in femoral SAT in our estrogen-deficient postmenopausal women, possibly contributing to the promotion of fat storage in the abdominal region after menopause.

\section{Potential Mechanisms for Regulation of Lipolysis by Estrogens}

The mechanisms by which estrogens regulate basal SAT lipolysis remain unclear. In vitro data support both genomic and non-genomic actions of estrogen in adipose tissue (16). There is increasing evidence that estrogens act through non-genomic mechanisms at the plasma membrane level, including the cyclic adenosine monophosphate and phosphoinositide cascades (16,34-37). Presumably, the effects of acute IV estrogen administration on basal lipolysis in the current study were through such rapid non-genomic mechanisms. To our knowledge, the only study that has investigated the effect of estrogen on a mediator of regional SAT lipolysis (LPL activity) in humans administered estrogens for 3 weeks (i.e., long enough for genomic mechanisms to occur) (38). In that study, treatment of postmenopausal women with oral ethinyl estradiol $(50 \mu \mathrm{g} / \mathrm{d})$ for 3 weeks resulted in increased adipose tissue lipoprotein lipase activity in femoral, but not abdominal, adipocytes (38). Thus, estrogens may influence femoral SAT basal lipolysis through transcriptional effects on adipose tissue lipoprotein lipase, possibly promoting the storage of triglyceride in femoral adipocytes. Rapid non-genomic mechanisms have not been evaluated in human abdominal and femoral SAT, and the current study was not designed to address such mechanisms. However, the findings that estrogens suppressed basal, but not insulin-mediated, femoral, and abdominal SAT lipolysis, suggest mechanisms that are not regulated by insulin.

\section{Study Limitations}

The current study had limitations that should be taken into account. First, use of the ethanol technique to monitor adipose tissue nutritive blood flow provides a qualitative, rather than a quantitative, evaluation of blood flow. Although regional differences in SAT blood flow have been detected in response to exercise and angiotensin II $(39,40)$, the ethanol technique may not be sensitive enough to detect regional blood flow differences in response to estrogens or insulin. Further, the possibility that there were quantitative day-to-day differences in nutritive blood flow cannot be excluded. If nutritive blood flow was higher on the EST day compared with the CON day, then the decreased Glyc IS may have been the result of increased local clearance of glycerol rather than reduced basal lipolysis. Nevertheless, the stability of Ethanol $_{\text {outflow/inflow }}$ throughout the experiments suggests that estrogens and insulin had little effect on regional SAT nutritive blood flow.

Second, there is evidence that dose, route, and duration of estrogen administration are important determinants of the effects on insulin action $(12,41,42)$. Therefore, our findings may be specific to the IV administration of a single $2.5 \mathrm{mg}$ dose of conjugated estrogens that raised plasma estradiol into the premenopausal, mid-luteal range. 
Third, it is not known why whole body lipolysis did not decrease despite the apparent reductions in abdominal and femoral SAT lipolysis. It is possible that differences in abdominal and femoral basal lipolysis on the EST and CON days reflected day-to-day variability, rather than an effect of EST; Glyc IS before EST infusion (time 0) were not measured. It is also possible that estrogens were less effective in decreasing basal lipolysis in other tissues that were not assessed (e.g., visceral adipose tissue, muscle), thereby contributing to the lack of a significant decrease in net whole-body basal lipolysis.

In summary, acute IV administration of conjugated estrogens reduced basal lipolysis in SAT, but basal whole-body lipolysis was not significantly altered. Estrogens did not alter insulinmediated suppression of either whole-body or SAT lipolysis. Suppression of basal lipolysis by estrogens in subcutaneous femoral and abdominal adipose tissue could contribute to the propensity of premenopausal women to accumulate fat in these regions. Additional studies will be needed to confirm the effects of estrogens on adipose tissue basal lipolysis, particularly during more prolonged estrogen therapy, and to elucidate the underlying mechanisms.

\section{Acknowledgments}

The authors thank Pam Wolfe, MS, for her statistical support, as well as the staffs of the University of Colorado at Denver and Health Sciences Center GCRC and Energy Balance Core of the Clinical Nutrition Research Unit (CNRU) for their assistance in conducting this study. The authors also thank the members of their research group for carrying out the day-to-day activities of the project and the study volunteers for their time and efforts. The following awards from the NIH supported this research: R01 AG18198, K01 AG19630 (REV), F32 AG05899 (WSG), AG18407 and AG19209 (RCH), M01 RR00051 (GCRC), P30 DK48520 (CNRU). W.S.G. was supported in part by a Hartford/ Jahnigen Center of Excellence Career Award.

\section{References}

1. Revilla R, Revilla M, Villa LF, Cortes J, Arribas I, Rico H. Changes in body composition in women treated with gonadotropin-releasing hormone antagonists. Maturitas 1998;31:63-68. [PubMed: 10091206]

2. Yamasaki H, Douchi T, Yamamoto S, Oki T, Kuwahata R, Nagata Y. Body fat distribution and body composition during GnRH agonist therapy. Obstet Gynecol 2001;97:338-342. [PubMed: 11239633]

3. Espeland MA, Stefanick ML, Kritz-Silverstein D, et al. Effect of postmenopausal hormone therapy on body weight and waist and hip girths. J Clin Endocrinol Metab 1997;82:1549-1556. [PubMed: 9141548]

4. Gambacciani M, Ciaponi M, Cappagli B, et al. Body weight, body fat distribution, and hormonal replacement therapy in early postmenopausal women. J Clin Endocrinol Metab 1997;82:414-417. [PubMed: 9024228]

5. Jensen LB, Vestergaard P, Hermann AP, et al. Hormone replacement therapy dissociates fat mass and bone mass, and tends to reduce weight gain in early postmenopausal women: a randomized controlled 5-year clinical trial of the Danish Osteoporosis Prevention Study. J Bone Miner Res 2003;18:333342. [PubMed: 12568411]

6. Kohrt WM, Ehsani AA, Birge SJ. HRT preserves increases in bone mineral density and reductions in body fat after a supervised exercise program. J Appl Physiol 1998;84:1506, 1512. [PubMed: 9572792]

7. Richelsen B, Pedersen SB, Moller-Pedersen T, Bak JF. Regional differences in triglyceride breakdown in human adipose tissue: effects of catecholamines, insulin, and prostaglandin $\mathrm{E}_{2}$. Metabolism 1991;40:990-996. [PubMed: 1895966]

8. Richelsen B. Increased alpha 2- but similar beta-adrenergic receptor activities in subcutaneous gluteal adipocytes from females compared with males. Eur J Clin Invest 1986;16:302-309. [PubMed: 3019701]

9. Mauriège P, Galitzky J, Berlan M, Lafontan M. Heterogeneous distribution of beta and alpha-2 adrenoceptor binding sites in human fat cells from various fat deposits: functional consequences. Eur J Clin Invest 1987;17:156-165. [PubMed: 3034620] 
10. Rebuffé-Scrive M, Lonnroth P, Marin P, Wesslau C, Björntorp P, Smith U. Regional adipose tissue metabolism in men and postmenopausal women. Int J Obes 1987;11:347-355. [PubMed: 3312052]

11. Bolinder J, Engfeldt P, Ostman J, Arner P. Site differences in insulin receptor binding and insulin action in subcutaneous fat of obese females. J Clin Endocrinol Metab 1983;57:455-461. [PubMed: 6348060]

12. Cucinelli F, Paparella P, Soranna L, et al. Differential effect of transdermal estrogen plus progestagen replacement therapy on insulin metabolism in postmenopausal women: relation to their insulinemic secretion. Eur J Endocrinol 1999;140:215-223. [PubMed: 10216516]

13. Kimmerle R, Heinemann L, Heise T, et al. Influence of continuous combined estradiol-norethisterone acetate preparations on insulin sensitivity in postmenopausal nondiabetic women. Menopause 1999;6:36-42. [PubMed: 10100178]

14. Van Pelt RE, Gozansky WS, Schwartz RS, Kohrt WM. Intravenous estrogens increase insulin clearance and action in postmenopausal women. Am J Physiol Endocrinol Metab 2003;285:E311E317. [PubMed: 12684221]

15. Bays H, Mandarino L, DeFronzo RA. Role of the adipocyte, free fatty acids, and ectopic fat in the pathogenesis of type 2 diabetes mellitus: peroxisomal proliferator-activator receptor agonists provide a rational therapeutic approach. J Clin Endocrinol Metab 2004;89:463-478. [PubMed: 14764748]

16. Mayes JS, Watson GH. Direct effects of sex steroid hormones on adipose tissues and obesity. Obes Rev 2004;5:197-216. [PubMed: 15458395]

17. Jensen MD, Martin ML, Cryer PE, Roust LR. Effects of estrogen on free fatty acid metabolism in humans. Am J Physiol 1994;266:E914-E920. [PubMed: 8023922]

18. DeFronzo RA, Tobin JD, Andres R. Glucose clamp technique: a method for quantifying insulin secretion and resistance. Am J Physiol 1979;237:E214-E223. [PubMed: 382871]

19. Liu D, Moberg E, Kollind M, Lins PE, Adamson U, MacDonald IA. Arterial, arterialized venous, venous and capillary blood glucose measurements in normal man during hyperinsulaemic euglycaemia and hypoglycaemia. Diabetologia 1992;35:287-290. [PubMed: 1563586]

20. Gilker CD, Pesola GR, Matthews DE. A mass spectrometric method for measuring glycerol levels and enrichments in plasma using ${ }^{13} \mathrm{C}$ and ${ }^{2} \mathrm{H}$ stable isotopic tracers. Anal Bio chem 1992;205:172178.

21. Steele R. Influences of glucose loading and of injected insulin on hepatic glucose output. Ann NY Acad Sci 1959;82:420-430. [PubMed: 13833973]

22. Simonsen L, Bulow J, Madsen J. Adipose tissue metabolism in humans determined by vein catheterization and microdialysis techniques. Am J Physiol 1994;266:E357-E365. [PubMed: 8166255]

23. Hickner RC, Rosdahl H, Borg I, Ungerstedt U, Jorfeldt L, Henriksson J. The ethanol technique of monitoring local blood flow changes in rat skeletal muscle: implications for microdialysis. Acta Physiol Scand 1992;146:87-97. [PubMed: 1442130]

24. Hickner RC, Fisher JS, Kohrt WM. Regional differences in interstitial glycerol concentration in subcutaneous adipose tissue of women. Am J Physiol 1997;273:E1033-E1038. [PubMed: 9374691]

25. Friedewald W, Levy R, Fredrickson D. Estimation of the concentration of low-density lipoprotein cholesterol in plasma, without the use of the preparative ultracentrifuge. Clin Chem 1972;18:499502. [PubMed: 4337382]

26. Gambacciani M, Ciaponi M, Cappagli B, De Simone L, Orlandi R, Genazzani AR. Prospective evaluation of body weight and body fat distribution in early postmenopausal women with and without hormonal replacement therapy. Maturitas 2001;39:125-132. [PubMed: 11514111]

27. Hassager C, Christiansen C. Estrogen/gestagen therapy changes soft tissue body composition in postmenopausal women. Metabolism 1989;38:662-665. [PubMed: 2661966]

28. Kristensen K, Pedersen SB, Vestergaard P, Mosekilde L. Hormone replacement therapy affects body composition and leptin differently in obese and non-obese postmenopausal women. J Endocrinol 1999;163:55-62. [PubMed: 10495407]

29. Douchi T, Kuwahata R, Yamasaki H, et al. Inverse relationship between the changes in trunk lean and fat mass during gonadotropin-releasing hormone agonist therapy. Maturitas 2002;42:31-35. [PubMed: 12020977] 
30. Rebuffé-Scrive M, Eldh J, Hafstrom L-O, Björntorp P. Metabolism of mammary, abdominal, and femoral adipocytes in women before and after menopause. Metabolism 1986;35:792-797. [PubMed: 3747836]

31. Ferrara CM, Lynch NA, Nicklas BJ, Ryan AS, Berman DM. Differences in adipose tissue metabolism between postmenopausal and perimenopausal women. J Clin Endocrinol Metab 2002;87:4166-4170. [PubMed: 12213866]

32. Darimont C, Delansorne R, Paris J, Ailhaud G, Negrel R. Influence of estrogenic status on the lipolytic action of parametrial adipose tissue in vivo: an in situ microdialysis study. Endocrinology 1997;138:1092-1096. [PubMed: 9048614]

33. Pedersen SB, Kristensen K, Hermann PA, Katzenellenbogen JA, Richelsen B. Estrogen controls lipolysis by up-regulating $\alpha 2 \mathrm{~A}$-adrenergic receptors directly in human adipose tissue through the estrogen receptor $\alpha$. Implications for the female fat distribution. J Clin Endocrinol Metab 2004;89:1869-1878. [PubMed: 15070958]

34. Garcia Dos Santos E, Dieudonne MN, Pecquery R, Le MV, Giudicelli Y, Lacasa D. Rapid nongenomic E2 effects on p42/p44 MAPK, activator protein-1, and cAMP response element binding protein in rat white adipocytes. Endocrinology 2002;143:930-940. [PubMed: 11861515]

35. Kelly MJ, Lewin ER. Rapid actions of plasma membrane estrogen receptors. Trends Endocrinol Metab 2001;12:152-155. [PubMed: 11295570]

36. Levin E. Cellular functions of the plasma membrane receptor. Trends Endocrinol Metab 1999;10:373377.

37. D’Eon TM, Souza SC, Aronovitz M, Obin MS, Fried SK, Greenberg AS. Estrogen regulation of adiposity and fuel partitioning. Evidence of genomic and non-genomic regulation of lipogenic and oxidative pathways. J Biol Chem 2005;280:35983-35991. [PubMed: 16109719]

38. Lindberg U-B, Crona N, Silfverstolpe G, Björntorp P, Rebuffé-Scrive M. Regional adipose tissue metabolism in postmenopausal women after treatment with exogenous sex steroids. Hormone Metab Res 1990;22:345-351.

39. Boschmann M, Ringel J, Klaus S, Sharma A. Metabolic and hemodynamic response of adipose tissue to angiotensin II. Obes Res 2001;9:486-491. [PubMed: 11500529]

40. Boschmann M, Rosenbaum M, Leibel RL, Segal KR. Metabolic and hemodynamic responses to exercise in subcutaneous adipose tissue and skeletal muscle. Int J Sports Med 2002;23:537-543. [PubMed: 12439767]

41. Lindheim SR, Duffy DM, Kojima T, Vijod MA, Stanczyk FZ, Lobo RA. The route of administration influences the effect of estrogen on insulin sensitivity in postmenopausal women. Fertil Steril 1994;62:1176-1180. [PubMed: 7957980]

42. Lindheim SR, Presser SC, Ditkoff EC, Vijod MA, Stanczyk FZ, Lobo RA. A possible bimodal effect of estrogen on insulin sensitivity in postmenopausal women and the attenuating effect of added progestin. Fertil Steril 1993;60:664-667. [PubMed: 8405521] 


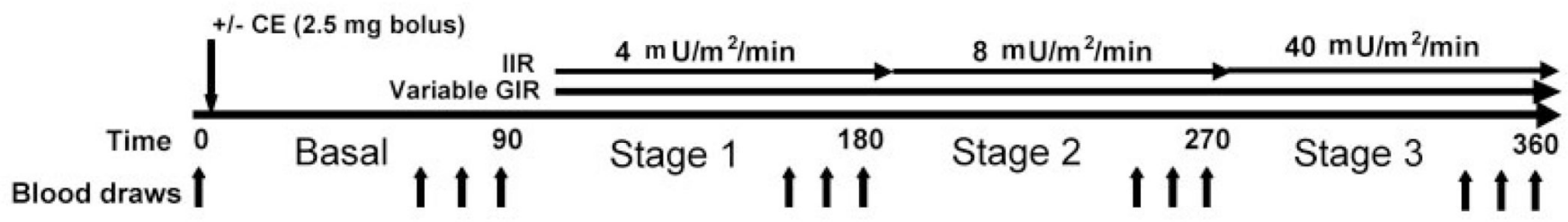

Figure 1.

Illustration of the 3-stage hyperinsulinemic, euglycemic clamp protocol. IIR, insulin infusion rate; GIR, glucose infusion rate. Blood samples were obtained at time 0 and at the 60,75 , and $90 \mathrm{~min}$ time-points during the basal period and stages $1\left(4 \mathrm{mU} / \mathrm{m}^{2} / \mathrm{min}\right), 2\left(8 \mathrm{mU} / \mathrm{m}^{2} / \mathrm{min}\right)$, and $3\left(40 \mathrm{mU} / \mathrm{m}^{2} / \mathrm{min}\right)$. Conjugated estrogens (CE) were given as an IV bolus $(2.5 \mathrm{mg})$ after the fasting blood samples (time 0 ) on one of the two (randomly determined) testing days. 


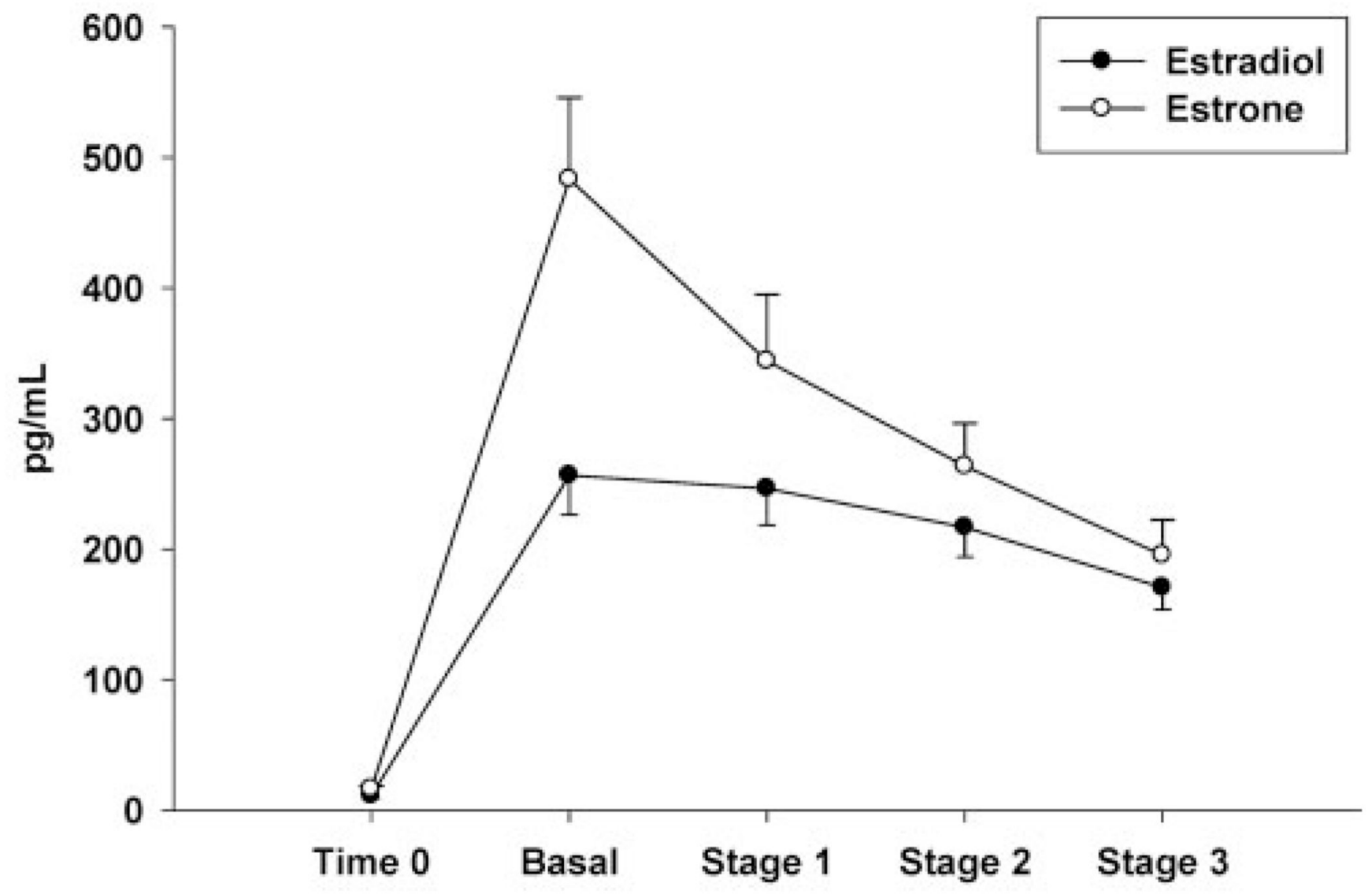

Figure 2.

Mean ( \pm standard error; $n=12$ ) serum estradiol and estrone concentrations on the EST day at time 0 (before IV conjugated estrogen bolus) and during the basal period and each stage of the hyperinsulinemic, euglycemic clamp. 

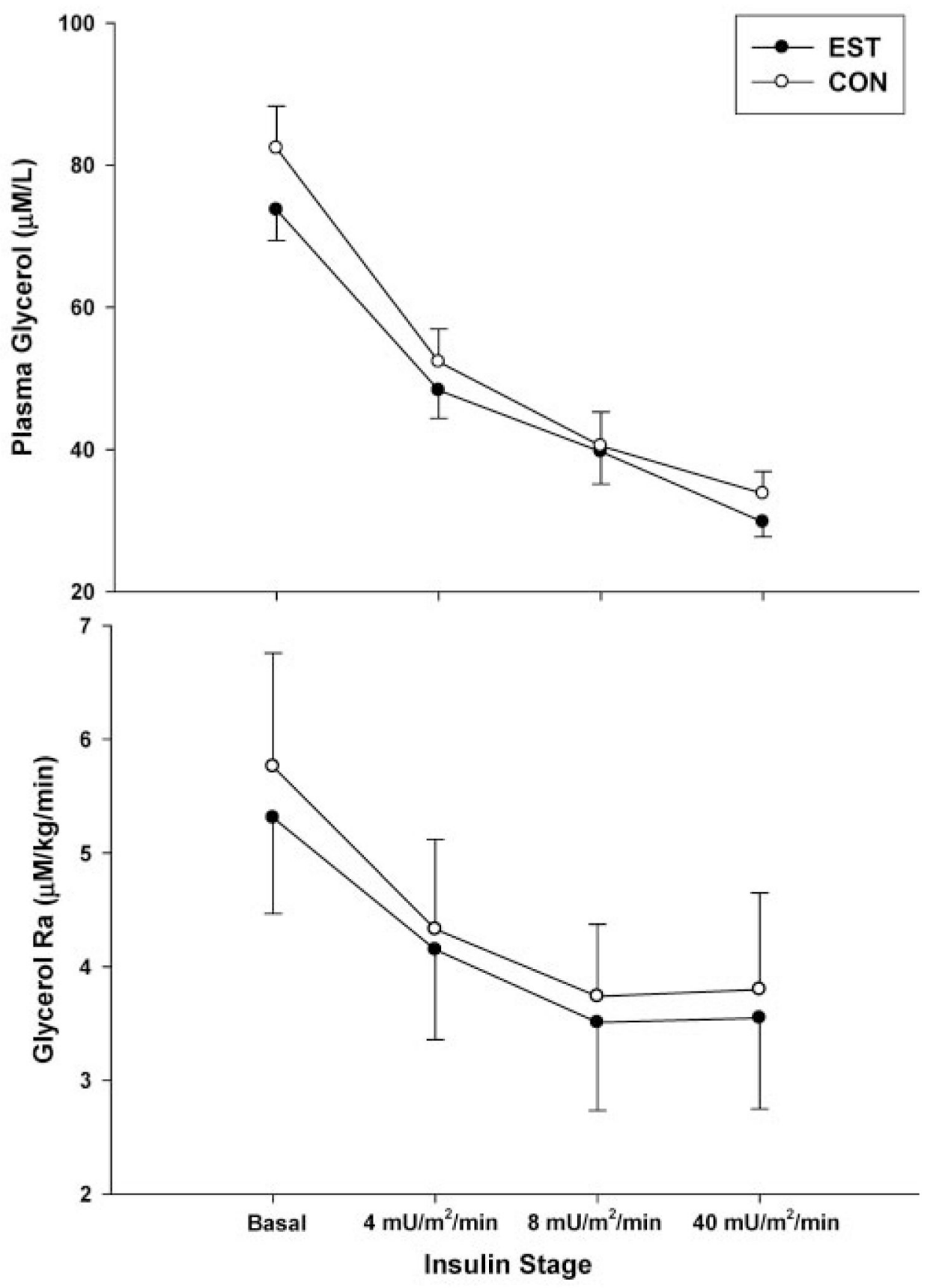

Figure 3.

Mean ( \pm standard error) serum glycerol concentrations $(n=12$; top panel $)$ and $\operatorname{Glyc}_{\mathrm{RA}}(n=$ 10 , bottom panel) during the basal period and each stage of the hyperinsulinemic, euglycemic clamp on the estrogen day (EST) compared with the control day (CON). There was a significant $(p<0.005)$ main effect of insulin stage, but not treatment day, on glycerol concentrations and Ra. 


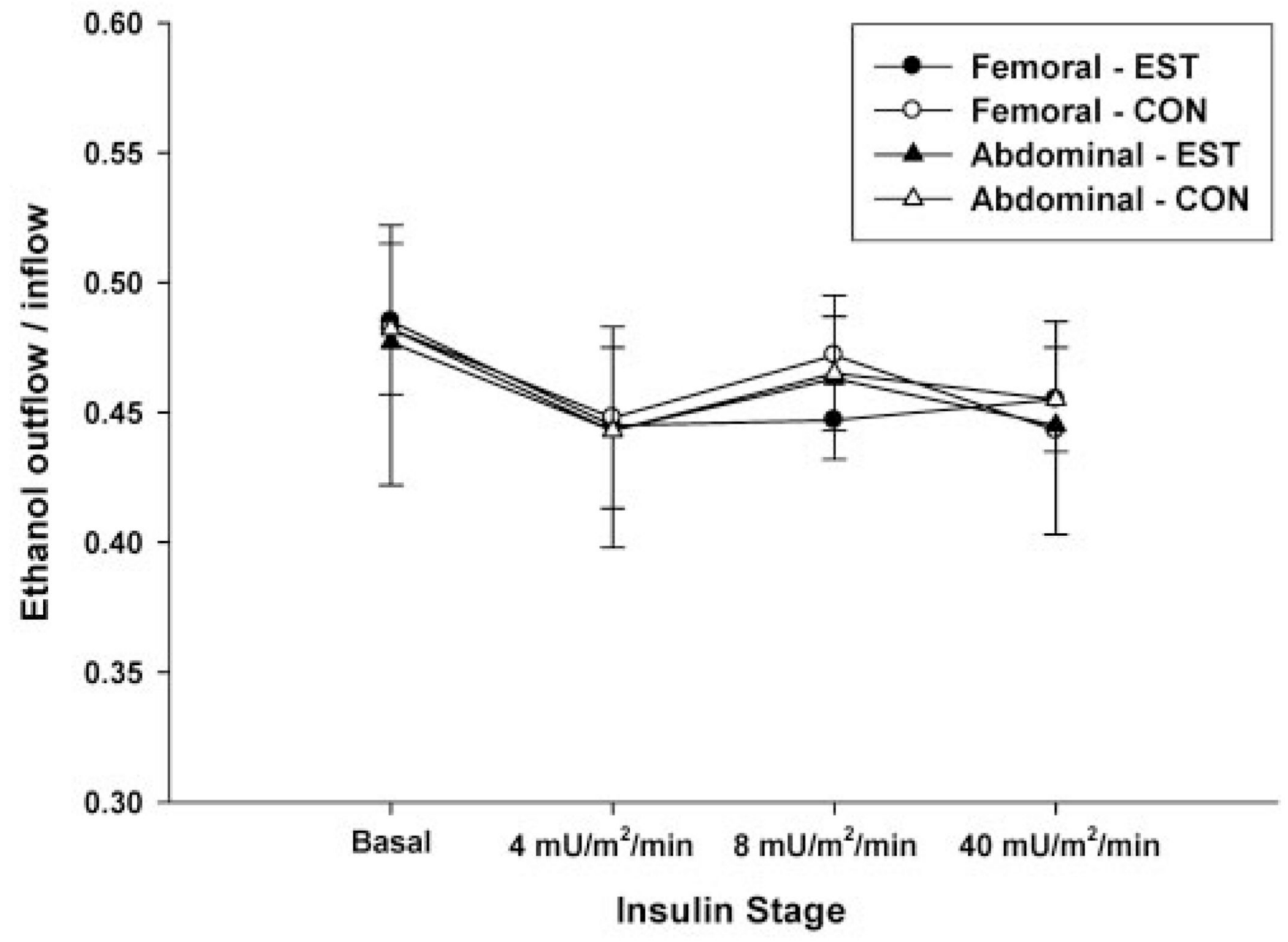

Figure 4.

Mean ( \pm standard error; $n=12$ ) femoral and abdominal subcutaneous adipose tissue nutritive blood flow (ethanol outflow/inflow ratio) throughout the hyperinsulinemic, euglycemic clamp on the estrogen day (EST) compared with the control day (CON). 


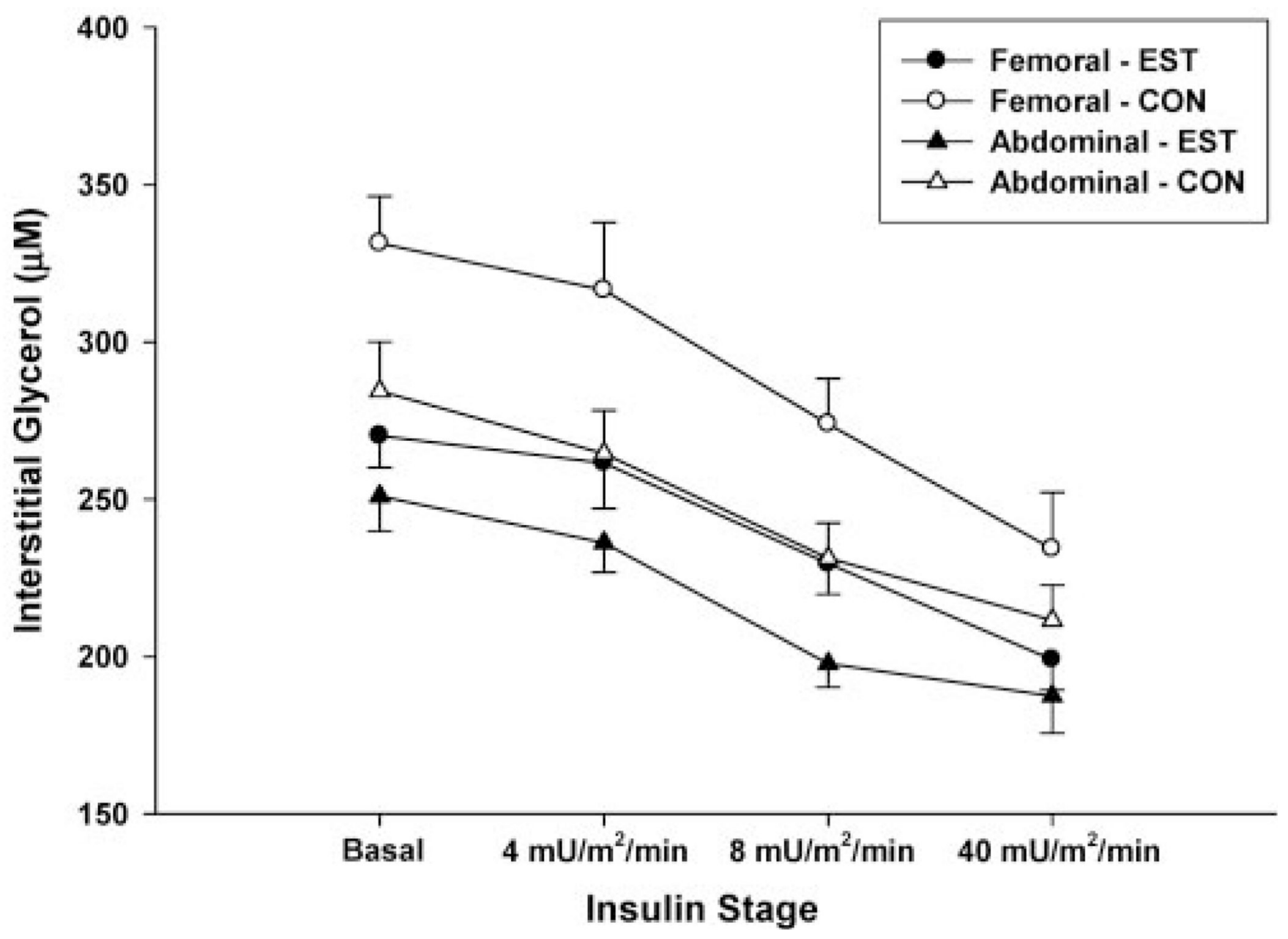

Figure 5 .

Mean ( \pm standard error; $n=12$ ) femoral and abdominal subcutaneous adipose tissue interstitial glycerol concentrations throughout the hyperinsulinemic, euglycemic clamp on the estrogen day (EST) compared with the control day (CON). There were significant main effects of: 1$)$ insulin stage $(p<0.001)$; 2$)$ treatment day $(p<0.05$, EST<CON); and 3$)$ fat region $(p=0.001$, abdominal $<$ femoral) on interstitial glycerol concentrations. 


\section{Table 1}

Subject characteristics $(n=12)$

\begin{tabular}{lc}
\hline Variable & $\begin{array}{c}\text { Mean } \pm \\
\text { standard deviation }\end{array}$ \\
\hline Age $(\mathrm{yr})$ & $56 \pm 4$ \\
Body mass $(\mathrm{kg})$ & $73.8 \pm 15.2$ \\
BMI $\left(\mathrm{kg} / \mathrm{m}^{2}\right)$ & $27.0 \pm 5.0$ \\
Waist girth $(\mathrm{cm})$ & $94.9 \pm 16.3$ \\
Fat mass $(\mathrm{kg})$ & $30.6 \pm 11.2$ \\
Years menopausal & $9 \pm 5$ \\
Total cholesterol (mM) & $5.17 \pm 0.93$ \\
High-density lipoprotein & \\
cholesterol (mM) & $1.47 \pm 0.36$ \\
Low-density lipoprotein \\
cholesterol (mM)
\end{tabular}




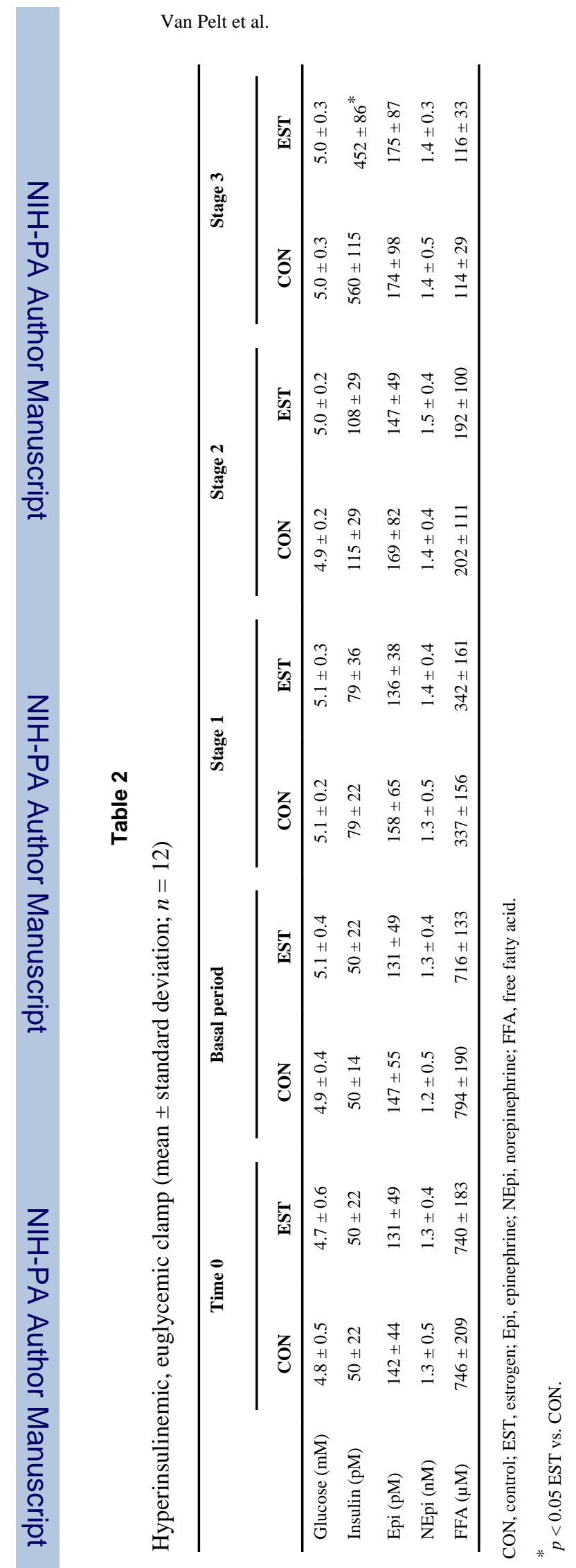

Obesity (Silver Spring). Author manuscript; available in PMC 2010 March 4. 